\title{
Descrição Anatômica de Espécies de Madeira Utilizadas na Construção Civil
}

\author{
Graziela Cury $^{1}$, Mario Tomazello Filho ${ }^{2}$ \\ ${ }^{1}$ Departamento de Botânica, Instituto de Ciências Biológicas - IB, Universidade de São Paulo - USP
}

${ }^{2}$ Departamento de Ciências Florestais, Escola Superior de Agricultura “Luiz de Queiroz" - ESALQ, Universidade de São Paulo - USP

\begin{abstract}
RESUMO
Este trabalho traz a descrição anatômica de cinco espécies de madeiras (Pachystroma ilicifolium, Esenbeckia leiocarpa, Cariniana estrellensis, Ocotea porosa e Cassia ferruginea), comumente utilizadas na construção civil. As descrições apresentadas demonstraram que as espécies do estudo podem ser separadas pela anatomia do lenho, o que indiretamente contribui não só com garantias de segurança, mas também com a conservação das espécies florestais.
\end{abstract}

Palavras-chave: identificação de madeiras, espécies florestais, anatomia do lenho.

\section{Anatomical Description of Wood Species Used in the Civil Construction}

\begin{abstract}
This work brings the anatomical description of five wood species (Pachystroma ilicifolium, Esenbeckia leiocarpa, Cariniana estrellensis, Ocotea porosa e Cassia ferruginea) usually used in the civil construction. The presented descriptions showed that the species in this study can be sorted by their wood anatomy - what contributes not only to the safety warranties but also to the conservation of forest species.
\end{abstract}

Keywords: wood identification, forest species, wood anatomy.

\section{INTRODUÇÃO}

As madeiras constituem-se, tradicionalmente, em um dos principais materiais empregados em todas as etapas da construção civil, pela diversidade de espécies com propriedades e usos diferenciados. As madeiras são, na prática, classificadas em pesada externa e interna; leve externa e interna estrutural; leve interna decorativa, de utilidade geral, em esquadrias e para assoalhos domésticos (Zenid, 2009).

Em inúmeros países, a madeira tem sido aplicada na construção de habitações e em estruturas, ao contrário do que ocorre em nosso País, no qual o potencial desse material biológico não tem sido devidamente explorado. Dentre os fatores que limitam tal emprego, destacam-se as restrições de natureza histórico-cultural, a escassez de mão-deobra qualificada e o desconhecimento das espécies e de suas propriedades, prejudicando a qualidade e reduzindo a vida útil das construções (Pedreschi et al., 2005). Atualmente, as novas limitações do uso da madeira devem-se às exigências da comprovação da origem, visando à sua utilização racional e sustentada, por meio da exploração de plantações e de populações florestais naturais manejadas.

Comumente, observa-se o uso inadequado da madeira por causa de erros de identificação da espécie 
e, em consequência, ocorre o comprometimento da vida útil e da segurança das estruturas e edificações. Verifica-se, ainda, a introdução de espécies de madeira no mercado de aspecto semelhante às tradicionais, embora com qualidade inferior para a aplicação a que se destinam (Gomes et al., 2002). Nesse aspecto, a correta identificação da espécie botânica da madeira proveniente de florestas nativas ou de reflorestamento, por meio da sua estrutura anatômica, é fundamental na preconização do uso em construção de edificações, estruturas ou pontes (Zenid, 1997). A anatomia da madeira é o ramo da ciência que analisa e descreve o arranjo dos elementos celulares do lenho das árvores, constituindo-se em valiosa ferramenta para a identificação das espécies tropicais (Ramalho, 1975). Dessa forma, a identificação das espécies baseia-se exclusivamente nas características macro e microscópicas de uma peça ou do lenho do tronco das árvores (IPT, 1985).

Há décadas recomenda-se a utilização dos caracteres anatômicos para a certificação da espécie de madeira, garantindo seu desempenho quando em uso, seja em relação à resistência natural a organismos xilófagos ou às suas propriedades físico-mecânicas (Record, 1949). No Brasil, é comum a ocorrência de erros de identificação das espécies de madeira no mercado distribuidor, ressaltando a necessidade de aplicação de técnica adequada de identificação baseada na análise da estrutura anatômica do lenho (Zenid, 1997). Ressalte-se, ainda, a utilização de múltiplos nomes comuns aplicados a uma espécie de madeira e de um mesmo nome para diferentes espécies no comércio. Por exemplo, o nome comum da madeira de "cumaru", representativa de cinco diferentes espécies no Estado do Pará (Souza et al., 2007).

Dessa forma, fica evidente a necessidade de estudos que analisem a estrutura anatômica do lenho de espécies utilizadas na construção civil, ressaltando-se ainda que, apesar de serem espécies já previamente descritas e encontradas na literatura, novas descrições certamente contribuem para tal identificação. Note-se que o lenho pode apresentar diversidade estrutural, resultante de adaptações funcionais e associadas ao hábito das plantas, e das condições edafo-climáticas (Dickison, 2000), podendo até mesmo árvores de uma mesma espécie apresentar variações morfológicas e anatômicas dentro de uma mesma população (Burley, 1982).

Pelo exposto, o presente trabalho tem como objetivo caracterizar a estrutura anatômica microscópica do lenho de cinco espécies arbóreas ocorrentes no Estado de São Paulo (Pachystroma ilicifolium Muell. Arg.; Esenbeckia leiocarpa Engl.; Cariniana estrellensis (Raddi) O. Ktze.; Ocotea porosa (Nus \& Mart.) Barroso, e Cassia ferruginea Schrad.), visando a contribuir para a sua correta identificação quando no comércio e em uso na construção civil, bem como para a sua preservação e para o seu uso sustentado.

\section{MATERIAL E MÉTODOS}

\section{1. Áreas de coleta}

As amostras de lenho das árvores das cinco espécies florestais foram coletadas nas seguintes localidades: Estação Experimental de Santa Rita do Passa Quatro, localizada no município de Santa Rita do Passa Quatro-SP, sob as coordenadas 2140’ S e 47³0’ W (Ocotea porosa (Nus \& Mart.) Barroso - Lauraceae e Cassia ferruginea Schrad. - Caesalpiniaceae); Reserva Florestal Mata de Santa Genebra, localizada entre os municípios de Campinas-SP e Piracicaba-SP, sob as coordenadas 2244' S e 4706' W (Pachystroma ilicifolium Muell. Arg. - Euphorbiaceae); Estação Experimental de Tupi, localizada no município de Piracicaba-SP, sob as coordenadas $22^{\circ} 43^{\prime} \mathrm{S}$ e $47^{\circ} 31^{\prime} \mathrm{W}$ (Esenbeckia leiocarpa Engl. - Rutaceae e Cariniana estrellensis (Raddi) O. Ktze - Lecythidaceae).

\subsection{Coleta do material}

Nas florestas naturais e plantações relacionadas, foram selecionadas árvores de cinco espécies, a partir de um levantamento de ocorrência de espécies arbóreas produtoras de madeira utilizadas comumente na construção civil no Estado de São Paulo. De três árvores adultas de cada espécie, foram extraídas amostras do lenho na altura do DAP $(1,30 \mathrm{~m})$ do tronco, por método não destrutivo (Cury et al., 2001), com extrator motorizado acoplado a uma sonda metálica. 


\subsection{Análise das amostras do lenho}

Para a análise anatômica microscópica, corposde-prova do lenho $\left(1 \mathrm{~cm}^{3}\right)$ foram obtidos a partir das amostras coletadas e fervidos em solução de água e glicerina (4:1) (Ferreirinha, 1958), para o amolecimento. Secções nos planos transversal, longitudinal tangencial e longitudinal radial (15$20 \mu \mathrm{m}$ de espessura) foram obtidas em micrótomo de deslize. As secções foram clarificadas com hipoclorito de sódio (50\%), coradas com safranina (1\%) e montadas em bálsamo do Canadá para obtenção de lâminas permanentes (Johansen, 1940) analisadas sob microscópio de luz.

Os dados quantitativos medidos foram frequência, diâmetro e comprimento de elementos de vasos, diâmetro de pontoações intervasculares, comprimento e espessura da parede das fibras e altura dos raios. Para a mensuração da espessura da parede das fibras e do comprimento dos vasos, e para a análise de apêndices nos elementos de vaso, foi realizada a dissociação dos elementos celulares por maceração de segmentos do lenho, segundo Franklin (1937). O número de medições foi fixado em $\mathrm{n}=10$ para diâmetro tangencial de pontoação e, para os demais parâmetros, foi fixado em $\mathrm{n}=30$. Para as quantificações do diâmetro das paredes das fibras e das pontoações intervasculares, utilizou-se um microscópio de luz com tambor micrométrico; e, para o diâmetro, o comprimento e a frequência de vasos, e a altura dos raios, foi utilizado microscópio de projeção em mesa em sala escura. Os valores obtidos foram convertidos em micrometros por meio de um fator de conversão. Para comparação entre as médias das cinco espécies (Tabela 1), foi realizada análise estatística utilizando o estudo com dados inteiramente casualizados, seguido do teste de Tukey, no nível de $5 \%$ de probabilidade para todas as variáveis quantificadas. Toda a análise foi realizada com base nas normas de IAWA Committee (1989).

\section{RESULTADOS E DISCUSSÃO}

\section{Pachystroma ilicifolium: Popularmente} conhecida como canxim, a madeira é dura, sendo de boa qualidade para a construção de vigas, ripas, rodapés e tábuas (Mainieri e Chimelo, 1989).

- Características anatômicas: vasos com porosidade difusa, frequência de $3 . \mathrm{mm}^{-2}$, solitários e múltiplos em cadeias radiais, forma da secção arredondada (Figura 1a), placas de perfuração simples, diâmetro tangencial de $71,4 \mu \mathrm{m}$, elementos de vaso com $0,55 \mathrm{~mm}$ de comprimento, com presença de um, dois ou ausência de apêndices (Figura 1d), tilos não abundantes, depósitos nos vasos pouco abundantes de cor marrom, pontoações intervasculares opostas, arredondadas, com diâmetro tangencial de $10,2 \mu \mathrm{m}$ e pontoações radiovasculares semelhantes às intervasculares. Parênquima axial em linhas finas ligando os poros (Figura 1a). Fibras com $1,23 \mathrm{~mm}$ de comprimento e paredes muito espessas. Raios unisseriados (Figura 1b), com 0,287 $\mathrm{mm}$ de altura, heterocelulares com células procumbentes e duas a três fileiras marginais de células quadradas e eretas (Figura 1c), não estratificados. Cristais presentes em células de parênquima axial (Figura 1c). Camadas de crescimento individualizadas pela variação do lume das fibras.

Esenbeckia leiocarpa: Popularmente conhecida como guarantã, a madeira é muito pesada, utilizada na construção civil, fabricação de assoalhos e carrocerias (Mainieri e Chimelo, 1989).

- Características anatômicas: vasos com porosidade difusa, frequência de $60 . \mathrm{mm}^{-2}$, agrupados em cadeias radiais de dois a quatro e alguns solitários, forma da secção arredondada (Figura 2a), placas de perfuração simples, com diâmetro tangencial de $68,1 \mu \mathrm{m}$, elementos vasculares com $0,3 \mathrm{~mm}$ de comprimento, com um ou ausência de apêndices (Figura 2d), tilos não abundantes, pontoações intervasculares alternas, arredondadas, com diâmetro tangencial de $4,8 \mu \mathrm{m}$, e pontoações radiovasculares semelhantes às intervasculares. Parênquima axial paratraqueal escasso (Figura 2a) e em linhas marginais. Fibras com 1,2 mm de comprimento e paredes muito espessas. Raios uni, bi, tri e multisseriados (Figura 2b), com altura de $0,306 \mathrm{~mm}$, heterocelulares com células procumbentes e uma a três fileiras marginais de células quadradas e eretas (Figura 2c), estratificados (Figura 2b). Cristais presentes em células do parênquima axial e do parênquima radial (Figura 2c). Camadas de crescimento individualizadas também pelo aumento do lume das fibras.

Cariniana estrellensis: Popularmente conhecida como jequitibá-branco, a madeira é moderadamente 

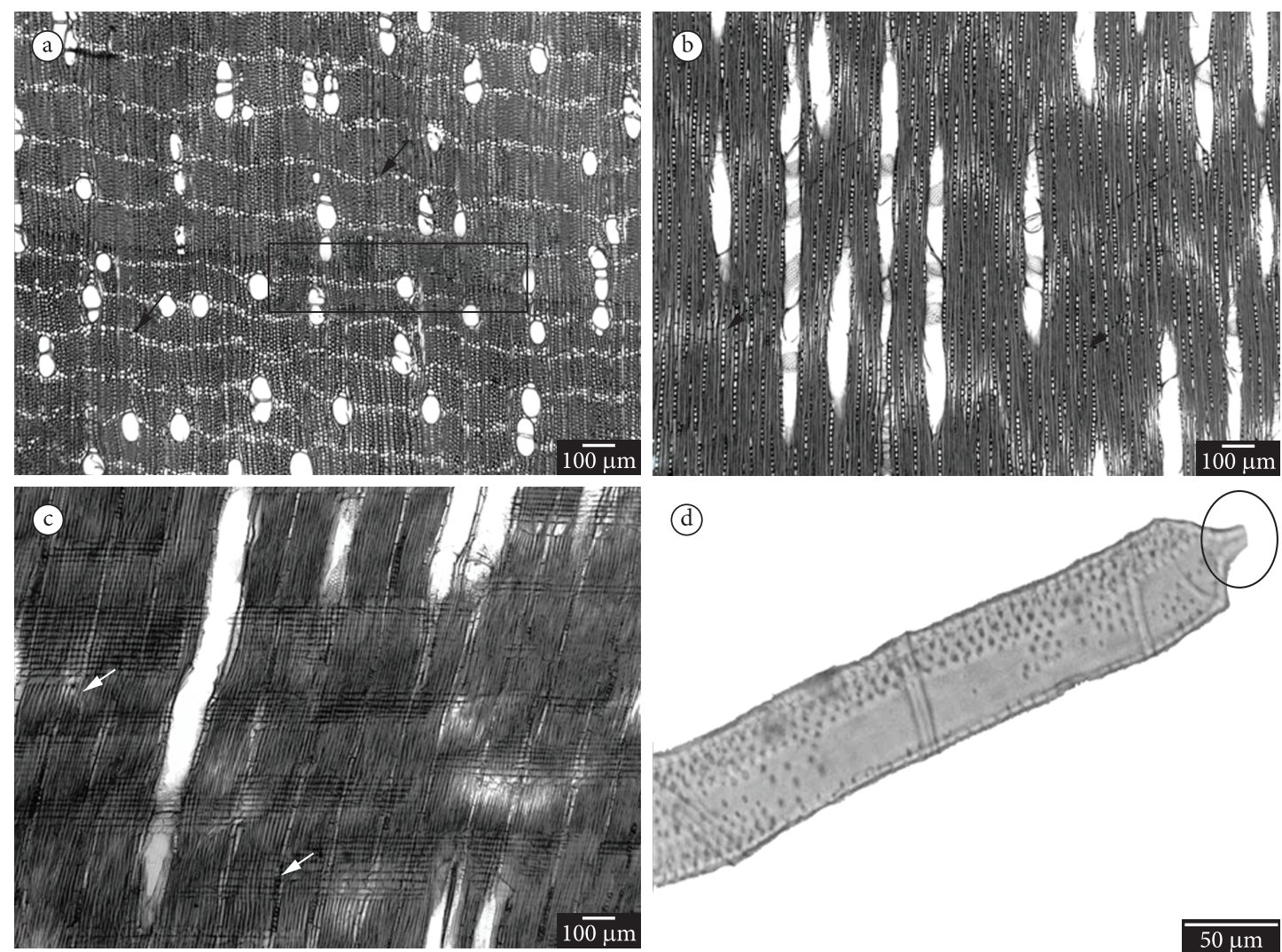

Figura 1. Pachystroma ilicifolium. a) Secção transversal evidenciando o parênquima axial (setas) e o limite entre camadas de crescimento (retângulo). b) Secção longitudinal tangencial evidenciando os raios (setas tracejadas). c) Secção longitudinal radial evidenciando os cristais em células do parênquima axial (setas brancas). d) Material macerado evidenciando um apêndice (círculo).

Figure 1. Pachystroma ilicifolium. a) Transection showing the axial parenchyma (arrows) and the boundary between the growth rings (rectangle). b) Longitudinal tangential section showing the rays (dotted arrows). c) Longitudinal radial section showing the crystals inside the cells of the axial parenchyma (white arrows). d) Macerated material showing one apendix (circle).

leve, usada na construção civil em obras internas (Almeida et al., 1998).

- Características anatômicas: vasos com porosidade difusa, frequência de $5 . \mathrm{mm}^{-2}$, solitários e múltiplos em cadeias radiais, forma da secção arredondada (Figura 3a), placas de perfuração simples, com diâmetro tangencial de $125,5 \mu \mathrm{m}$, elementos vasculares com $0,4 \mathrm{~mm}$ de comprimento, com presença de um, dois ou ausência de apêndices (Figura 3d), tilos não abundantes, pontoações intervasculares alternas, arredondadas, com diâmetro tangencial de $10,0 \mu \mathrm{m}$, e pontoações radiovasculares semelhantes às intervasculares. Parênquima axial em linhas finas, formando um reticulado com os raios (Figura 3a). Fibras com 1,53 mm de comprimento e paredes muito espessas. Raios trisseriados (Figura 3b) e alguns unisseriados, com 0,334 $\mathrm{mm}$ de altura, homocelulares (Figura 3c) com todas as células procumbentes. Cristais presentes em células de parênquima axial (Figura 3 b,c). Sílica presente em células de parênquima axial e radial. Camadas de crescimento individualizadas pela variação do lume das fibras.

Ocotea porosa: Popularmente conhecida como imbuia, a madeira é moderadamente pesada, sendo utilizada na fabricação de móveis, tábuas para assoalhos e vigas (Mainieri \& Chimelo, 1989).

- Características anatômicas: vasos com porosidade difusa, frequência de $10 . \mathrm{mm}^{-2}$, solitários e múltiplos, forma da secção arredondada (Figura 4a), placas de perfuração simples, diâmetro tangencial de $94,8 \mu \mathrm{m}$, elementos vasculares com $0,5 \mathrm{~mm}$ de comprimento, com um, dois ou ausência de apêndices (Figura 4d), 

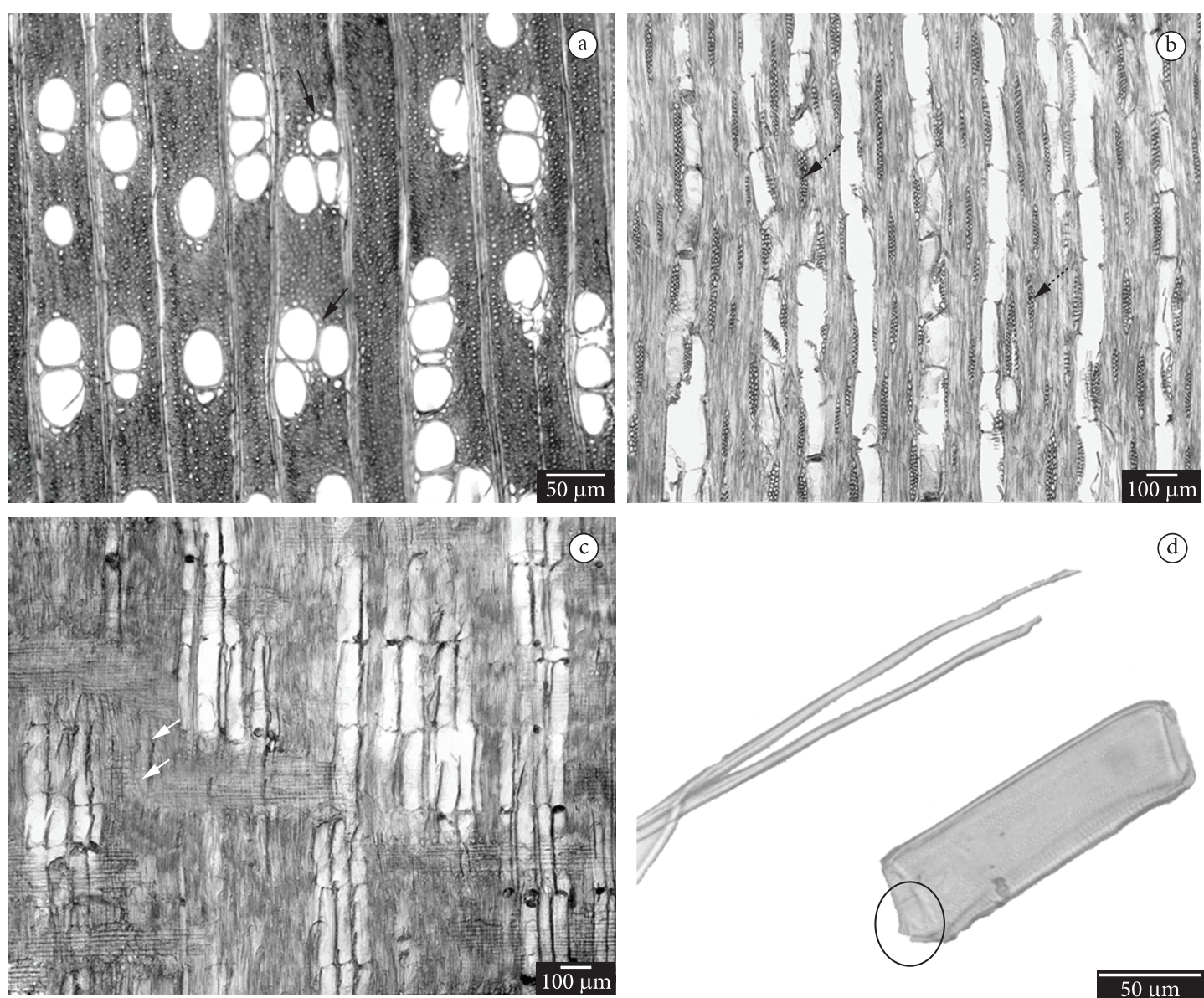

(d)

Figura 2. Esenbeckia leiocarpa. a) Secção transversal evidenciando o parênquima axial (setas). b) Secção longitudinal tangencial evidenciando os raios (setas tracejadas). Secção longitudinal radial evidenciando os cristais em células do parênquima axial e radial (setas brancas). d) Material macerado evidenciando um apêndice (círculo).

Figure 2. Esenbeckia leiocarpa. a) Transection showing the axial parenchyma (arrows). b) Longitudinal tangential section showing the rays (dotted arrows). c) Longitudinal radial section showing the crystals inside the cells of the axial and radial parenchyma (white arrows). d) Macerated material showing one apendix (circle).

tilos não abundantes, depósitos nos vasos pouco abundantes de cor marrom claro, pontoações intervasculares alternas, arredondadas, com diâmetro tangencial de $11,0 \mu \mathrm{m}$, pontoações radiovasculares semelhantes às intervasculares. Fibras septadas, com $1 \mathrm{~mm}$ de comprimento e paredes delgadas a espessas. Parênquima axial paratraqueal vasicêntrico e algumas células difusas (Figura 4a). Raios bisseriados na maioria e alguns trisseriados (Figura 4b), altura de 0,264 mm, heterocelulares com células procumbentes e uma fileira marginal de células quadradas e eretas (Figura 4c). Camadas de crescimento distintas, individualizadas pelo achatamento do lume das fibras.
Cassia ferruginea: Popularmente conhecida como canafístula, a madeira é pesada, sendo utilizada na fabricação de vigas (Almeida et al., 1998).

- Características anatômicas: vasos com porosidade difusa, frequência de $5 . \mathrm{mm}^{-2}$, solitários na maioria e alguns múltiplos de dois a três, forma da secção arredondada (Figura 5a), placas de perfuração simples, com diâmetro tangencial de 131,3 $\mu \mathrm{m}$, elementos vasculares com $0,25 \mathrm{~mm}$ de comprimento, com um ou ausência de apêndices (Figura 5d), tilos abundantes, depósitos nos vasos abundantes de cor marrom, pontoações intervasculares alternas, arredondadas, guarnecidas, com 6,1 $\mu \mathrm{m}$ de diâmetro tangencial, 

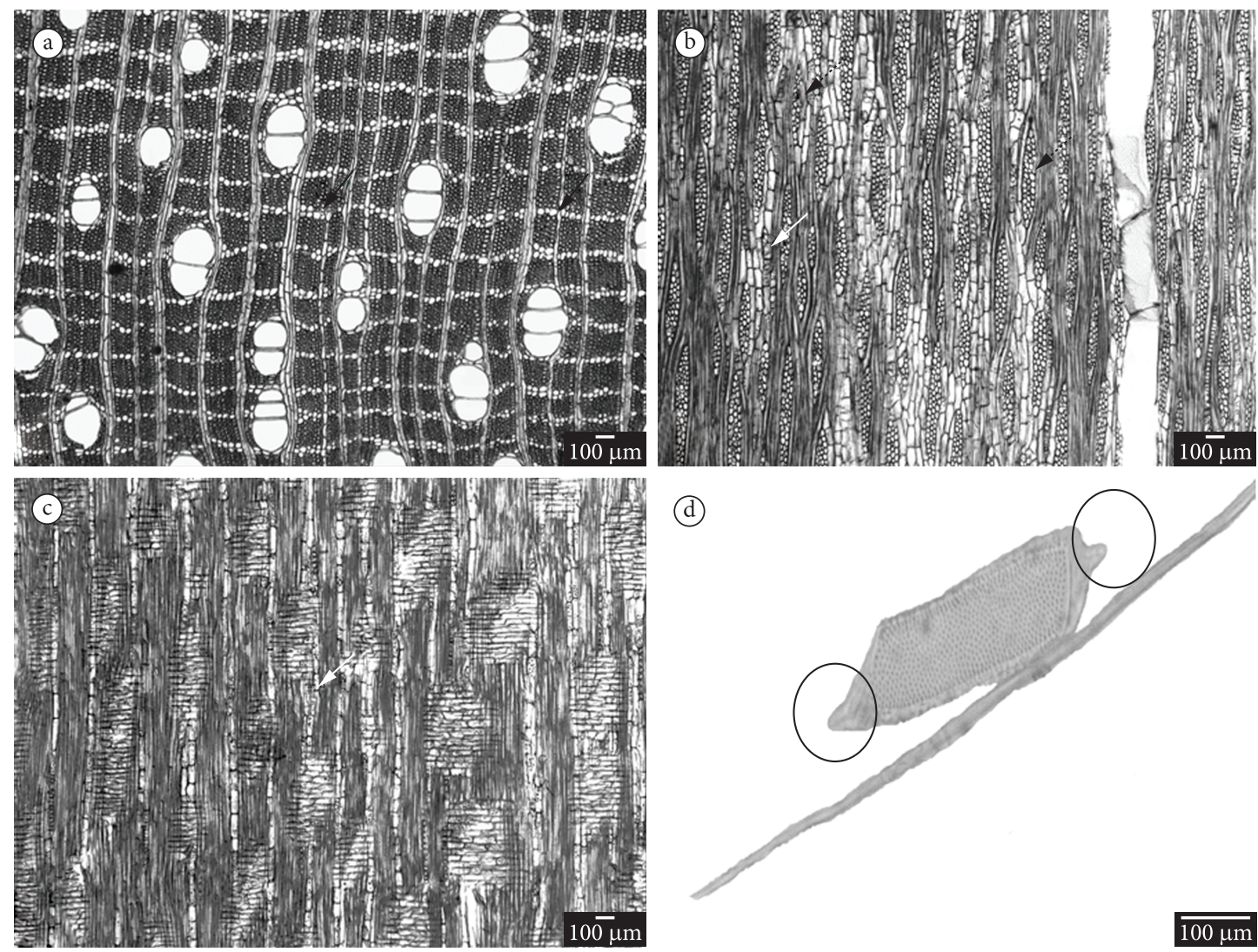

Figura 3. Cariniana estrellensis. a) Secção transversal evidenciando o parênquima axial (setas). b) Secção longitudinal tangencial evidenciando os raios (setas tracejadas) e cristais em células do parênquima axial (seta branca). c) Secção longitudinal radial evidenciando os cristais em células do parênquima axial (seta branca). d) Material macerado evidenciando dois apêndices (círculos).

Figure 3. Cariniana estrellensis. a) Transection showing the axial parenchyma (arrows). b) Longitudinal tangential section showing the rays (dotted arrows) and crystals inside the cells of the axial parenchyma (white arrows). c) Longitudinal radial section showing the crystals inside the cells of the axial parenchyma (white arrows). d) Macerated material showing two apendix (circles).

pontoações radiovasculares semelhantes às intervasculares. Parênquima axial paratraqueal aliforme losangular (Figura 5a) e linhas de parênquima marginal. Fibras septadas com $1 \mathrm{~mm}$ de comprimento e paredes de delgadas a espessas. Raios uni e bisseriados (Figura 5b), com altura de $0,183 \mathrm{~mm}$, homocelulares com todas as células procumbentes (Figura $5 \mathrm{c}$ ). Camadas de crescimento também individualizadas pelo achatamento do lume das fibras.

Em relação às características úteis na separação das espécies, destacam-se: a frequência de vasos em E. leiocarpa; as pontoações intervasculares opostas em P. ilicifolium; o diâmetro tangencial das pontoações intervasculares em E. leiocarpa e em C. ferruginea; o diâmetro tangencial dos vasos em O. porosa; o comprimento das fibras e dos elementos de vaso em C. estrellensis; as pontoações guarnecidas em C. ferruginea.

No que se refere às pontoações guarnecidas, estas ocorrem em cerca de 50 famílias de Angiospermas, entre as quais Leguminosae, Vochysiaceae e Myrtaceae (Carlquist, 2001; Détienne \& Jaquet, 1983; Metcalfe \& Chalk, 1950), e seu valor taxonômico é citado por diversos autores (Metcalfe \& Chalk, 1950; Butterfield \& Meylan, 1974; van Vliet \& Baas, 1984; Baas, 1982). Sua presença pode ser reconhecida como um caráter diagnóstico importante sob o ponto de vista taxonômico, pois tais pontoações estão restritas a certas famílias e algumas ordens (Bailey, 1933).

A descrição da anatomia do lenho de espécies de madeira utilizadas na construção civil é apresentada 

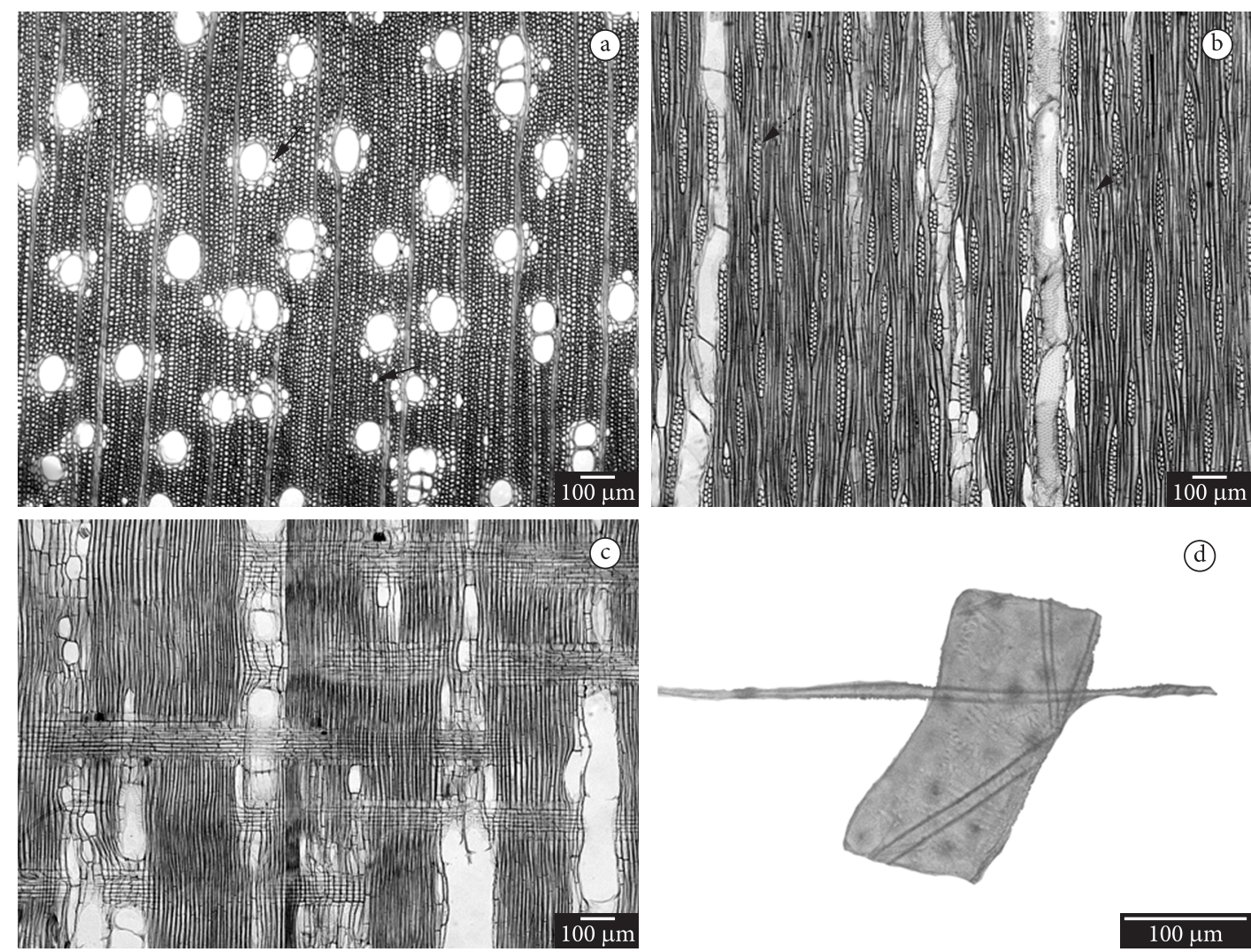

$100 \mu \mathrm{m}$

Figura 4. Ocotea porosa. a) Secção transversal evidenciando o parênquima axial (setas). b) Secção longitudinal tangencial evidenciando os raios (setas tracejadas). c) Secção longitudinal radial. d) Material macerado.

Figure 4. Ocotea porosa. a) Transection showing the axial parenchyma (arrows). b) Longitudinal tangential section showing the rays (dotted arrows). c) Longitudinal radial section. d) Macerated material.

na literatura por inúmeros autores, como Mainieri \& Pereira (1965), Mainieri \& Camargo (1967), Barbosa et al. (1978), Mainieri (1983), Tomazello Filho et al. (1984) e Mainieri \& Chimelo (1989). No entanto, há diferenças entre a descrição da literatura e a do presente trabalho, como as fibras de espessura da parede média e a demarcação das camadas de crescimento pelo achatamento do seu lume indicadas no lenho de P. ilicifolium por Mainieri \& Camargo (1967) e Mainieri \& Chimelo (1989); o diâmetro tangencial das pontoações intervasculares de $3 \mu \mathrm{m}$ no lenho de E. leiocarpa por Mainieri \& Chimelo (1989), sendo de $5 \mu \mathrm{m}$ neste trabalho; os vasos de 429-650 $\mu \mathrm{m}$ de comprimento, com apêndice em uma das extremidades e fibras de parede de delgada a média no lenho de C. estrellensis por Barbosa et al. (1978) e Mainieri e Chimelo (1989), diferindo de $400 \mu \mathrm{m}$, com um, dois e ausência de apêndices e muito espessa neste trabalho; as placas de perfuração ocasionalmente múltiplas em relação à simples, diâmetro tangencial dos vasos com $89 \mu \mathrm{m}$, em vez de $95 \mu \mathrm{m}$, e elementos vasculares de $0,6 \mathrm{~mm}$ de comprimento em relação aos de $0,5 \mathrm{~mm}$ no lenho de O. porosa descritos por Mainieri \& Chimelo (1989) e no presente trabalho; as pontoações intervasculares são guarnecidas e de diâmetro tangencial de 9-12 $\mu \mathrm{m}$ no lenho de C. ferruginea por Mainieri \& Chimelo (1989) e pontoações não guarnecidas e diâmetro de $6 \mu \mathrm{m}$, no presente trabalho.

O diâmetro e o comprimento dos vasos determinam a eficiência e a segurança na condução da seiva, sendo os curtos e de pequeno diâmetro mais seguros, e os mais longos e largos, mais eficientes (Zimmermann, 1982, 1983). Estudos da anatomia do lenho de espécies das famílias Asteraceae, Goodeniaceae, Campanulaceae, Brassicaceae e 

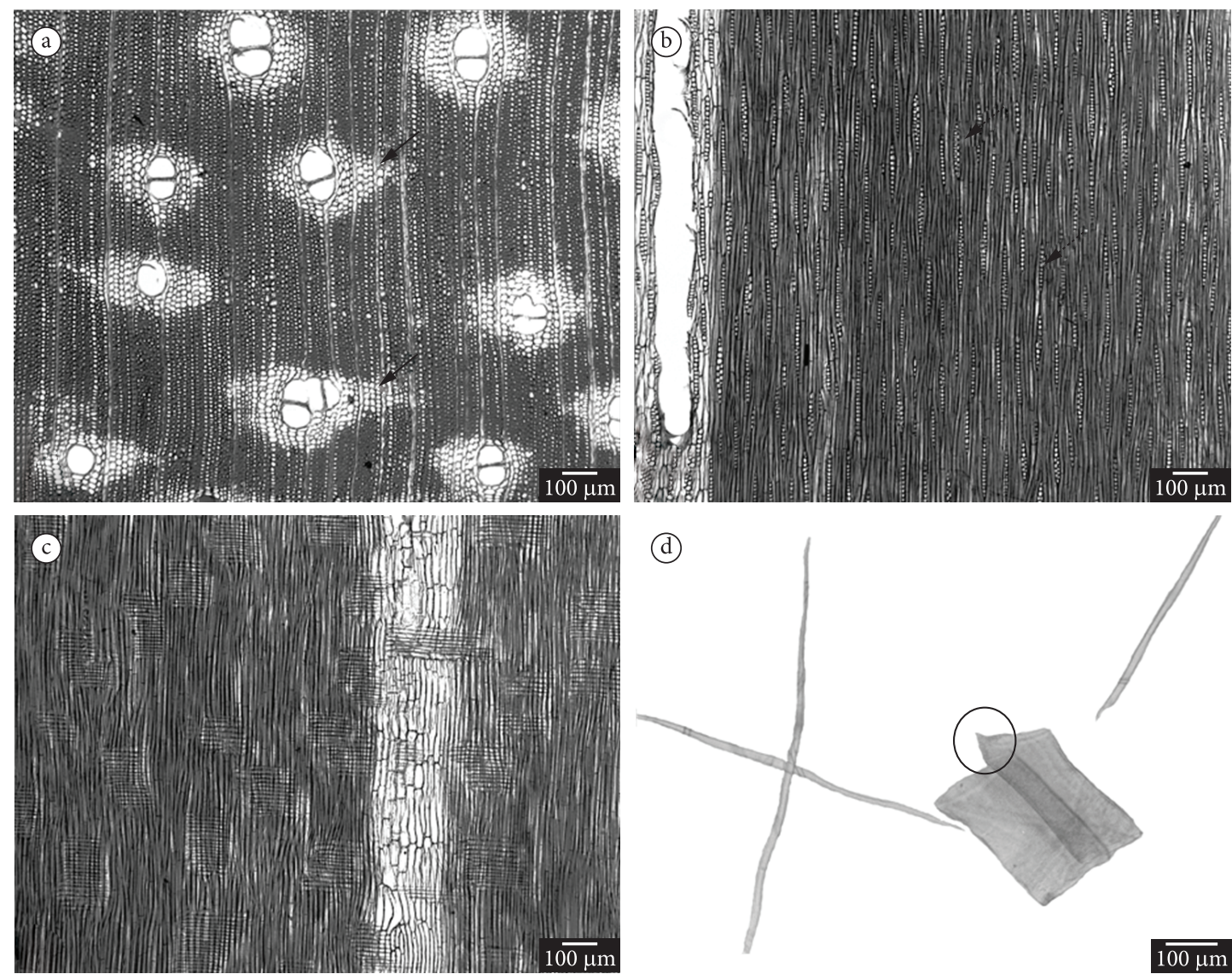

Figura 5. Cassia ferruginea. a) Secção transversal evidenciando o parênquima axial setas). b) Secção longitudinal tangencial evidenciando os raios (setas tracejadas). c) Secção longitudinal radial. d) Material macerado evidenciando a presença de um apêndice círculo.

Figure 5. Cassia ferruginea. a) Transection showing the axial parenchyma (arrows). b) Longitudinal tangential section showing the rays (dotted arrows). c) Longitudinal radial section. d) Macerated material showing one apendix (circle).

Tabela 1. Comparação das médias após análise estatística. $(\mathrm{F}=$ frequência; $\mathrm{DT}=$ diâmetro tangencial; $\mathrm{C}=$ comprimento; PIV = pontoação intervascular; $\mathrm{A}$ = altura).

Table 1. Means comparison after statistical analysis $(\mathrm{F}=$ frequency; $\mathrm{DT}=$ tangential diameter; $\mathrm{C}=$ length; $\mathrm{AP}=$ appendix; PIV = intervessel pitting; $\mathrm{A}=$ height).

\begin{tabular}{|c|c|c|c|c|c|c|}
\hline \multirow{2}{*}{ Espécie } & \multicolumn{3}{|c|}{ Vasos } & PIV & Fibras & Raios \\
\hline & $\mathbf{F}\left(\mathbf{m m}^{2}\right)$ & $\mathrm{DT}(\mu \mathrm{m})$ & $\mathrm{C}(\mathrm{mm})$ & DT $(\mu \mathrm{m})$ & $\mathrm{C}(\mathrm{mm})$ & $A(\mathbf{m m})$ \\
\hline Pachystroma ilicifolium & $3^{\mathrm{a}}$ & $71,4^{\mathrm{a}}$ & $0,55^{\mathrm{a}}$ & $10,2^{\mathrm{a}}$ & $1,23^{\mathrm{a}}$ & $0,28^{\mathrm{a}, \mathrm{b}}$ \\
\hline Esenbeckia leiocarpa & $60^{\mathrm{b}}$ & $68,1^{\mathrm{a}}$ & $0,30^{\mathrm{b}}$ & $4,8^{\mathrm{b}}$ & $1,20^{\mathrm{a}}$ & $0,30^{\mathrm{a}, \mathrm{b}}$ \\
\hline Cariniana estrellensis & $5^{\mathrm{a}}$ & $125,5^{\mathrm{b}}$ & $0,40^{\mathrm{b}}$ & $10,0^{\mathrm{a}}$ & $1,53^{\mathrm{b}}$ & $0,33^{\mathrm{b}}$ \\
\hline Ocotea porosa & $10^{\mathrm{b}}$ & $94,8^{c}$ & $0,50^{\mathrm{a}}$ & $11,0^{\mathrm{a}}$ & $1,00^{c}$ & $0,26^{\mathrm{a}}$ \\
\hline Cassia ferruginea & $5^{\mathrm{a}}$ & $131,3^{\mathrm{b}}$ & $0,25^{c}$ & $6,1^{\mathrm{c}}$ & $1,00^{c}$ & $0,18^{c}$ \\
\hline
\end{tabular}

a,b,c, Médias seguidas pela mesma letra na linha não diferem entre si pelo teste de Tukey a 5\% de probabilidade. 
dos gêneros Echium e Euphorbia identificaram elementos de vaso mais estreitos e mais curtos, maior número de vasos por grupo, elementos imperfurados mais curtos e raios mais curtos, estando alguns fatores correlacionados com o xeromorfismo. A adaptação ao grau de umidade do solo e a taxa de transpiração, a sazonalidade hídrica e a necessidade de investimento em resistência mecânica refletem os principais mecanismos evolutivos do xilema nas plantas (Carlquist, 1975, 2001) e levam a diferenças estruturais em amostras de uma mesma espécie.

\section{CONCLUSÕES}

Para as madeiras utilizadas na construção civil, os parâmetros anatômicos devem ser analisados, considerando-se que, apesar da grande diversidade das espécies, o comércio de madeiras é caracterizado por restrito número (Zenid, 1997). Esta constatação deve-se à identificação errônea da madeira nas madeireiras e nas construtoras, resultando em estruturas de baixa durabilidade, necessitando da substituição das peças afetadas ou de reforço estrutural, além do comprometimento da imagem da madeira como material na construção civil. Desta forma, todo projeto deve incluir a identificação correta das espécies e atender as características físico-mecânicas da madeira, visando contribuir não só com a segurança de edificações, mas também com a preservação e o uso sustentado das espécies florestais.

Este trabalho mostra que as descrições anatômicas das madeiras empregadas na construção civil permitem a identificação e a separação dessas espécies. Apesar de apresentar diferenças com os dados encontrados na literatura, este trabalho também destaca a importância da comparação entre indivíduos de uma mesma espécie, porém provenientes de lugares diferentes, pois, em função disto, podem apresentar diferenças em sua estrutura anatômica. Dessa forma, é de extrema importância ter conhecimento da variação da estrutura anatômica que pode ocorrer nos indivíduos de uma mesma espécie. Essa variação deve ser considerada quando é realizada a identificação com a finalidade de aplicações de suas propriedades, sejam elas na construção civil, sejam em qualquer outra não menos importante.

\section{AGRADECIMENTOS}

Os autores agradecem à Fundação de Amparo à Pesquisa do Estado de São Paulo (FAPESP Processo $n^{\circ}$ 2000/08499-4), pela concessão da Bolsa de Mestrado para a primeira autora; aos Técnicos de Laboratório Antônio Carlos F. Barbosa e Maria Aparecida C. Bermudes, pelo auxílio na montagem das lâminas histológicas, e ao Departamento de Botânica (IB-USP), pela utilização dos recursos de microscopia.

\section{STATUS DA SUBMISSÃO}

Recebido: 03/12/2010

Aceito: 09/08/2011

Resumo publicado online: 25/08/2011

Artigo completo publicado: 30/09/2011

\section{AUTOR(ES) PARA CORRESPONDÊNCIA}

\section{Graziela Cury}

Departamento de Botânica, Instituto de Biociências - IB, Universidade de São Paulo - USP, Rua do Matão, 277, Cidade Universitária, Butantã, CEP 05508-090, São Paulo, SP, Brasil e-mail: grazielacury@hotmail.com

\section{Mario Tomazello Filho}

Departamento de Ciências Florestais - LCF, Escola Superior de Agricultura "Luiz de Queiroz" - ESALQ, Universidade de São Paulo - USP, Av. Pádua Dias, 11, CEP 13418-900, Piracicaba, SP, Brasil e-mail: mtomazel@esalq.usp.br

\section{REFERÊNCIAS}

Almeida SP., Proença CEB., Sano SM., Ribeiro JF. Cerrado: espécies vegetais úteis. Planaltina: EMBRAPA; 1998.

Baas P. Systematic, phylogenetic and ecological wood anatomy: history and perspectives. In: Baas P, editor. New perspectives in wood anatomy. Boston: Martinus Nijhoff, Dr. Junk Publishers; 1982.

Bailey IW. The cambium and its derivate tissues VIII: structure, distribution and diagnostic significance of 
the vestured pits in dicotyledons. Journal Arnold Arbor $1933 ; 14: 259-273$.

Barbosa O, Baitello JB, Mainieri C, Montagna RG, Negreiros OC. Identificação e fenologia de espécies arbóreas da Serra da Cantareira (São Paulo). Silvicultura em São Paulo 1978; 11(12):1-168.

Burley J. Genetic variation in wood properties. In: Baas P, editor. New perspectives in wood anatomy. Boston: Martinus Nijhoff, Dr. Junk Publishers; 1982.

Butterfield BG, Meylan BA. Vestured vessel and fibers pits in Persoonia turo A. Cunn. (Proteaceae). IAWA Bulletin 1974; 1:10-15.

Carlquist S. Ecological strategies of xylem evolution. London: University of California Press; 1975.

Carlquist S. Comparative wood anatomy: systematic, ecological and evolutionary aspects of dicotyledons wood. Berlin: Springer Verlag; 2001.

Cury G, Tomazello Filho M, Lisi CS. Aplicação de método não destrutivo na coleta de amostras de madeira de espécies arbóreas nativas para estudo anatômico. In: Anais do I Simpósio Brasileiro de Pós-Graduação em Engenharia Florestal; 2001; Santa Maria. Santa Maria: Universidade Federal de Santa Maria; 2001. p. 80-89.

Détienne P, Jacquet P. Atlas d'indentification des bois de I’Amazonie et régions voisines. Nogent-sur-Marne: Centre Technique Forestier Tropical; 1983.

Dickison WC. Integrative Plant Anatomy. London: Academic Press; 2000.

Ferreirinha MP. Glossário internacional dos termos usados em anatomia de madeiras. Lisboa: Ministério do Ultramar, Junta de Investigações do Ultramar; 1958.

Franklin GL. Permanent preparations of macerated wood fibers. Tropical woods 1937; 49:21-22.

Gomes JI, Ferreira GC, Urbinati C. Anatomia $e$ identificação de madeiras amazônicas. Belém: Embrapa Amazônia Oriental; 2002.

International Association of Wood Anatomists - IAWA Committee. List of microscopic features for hardwood identification. IAWA Bulletin 1989; 10:219-332.

Instituto de Pesquisas Tecnológicas - IPT. Madeira: o que é e como pode ser processada e utilizada. São Paulo: IPT, Divisão de Madeiras; 1985.

Johansen DA. Plant microtechnique. New York: Mc Graw, Hill Book Company; 1940.

Mainieri C. Manual de identificação das principais madeiras comerciais brasileiras. São Paulo: IPT; 1983.
Mainieri C, Camargo MJP. Estudo anatômico de algumas madeiras brasileiras de parênquima apotraqueal zonado. São Paulo: IPT; 1967.

Mainieri C, Chimelo JP. Fichas de características das madeiras brasileiras. São Paulo: IPT; 1989.

Mainieri C, Pereira JA. Madeiras do Brasil, sua caracterização macroscópica, usos comuns e índices qualitativos, físicos e mecânicos. Separata de Anuário Brasileiro de Economia Florestal 1965; 17:255.

Metcalfe CR, Chalk L. Anatomy of the Dicotyledons: leaves, stem and wood in relation to taxonomy with notes on economic uses. Oxford: Clarendon Press; 1950.

Pedreschi R, Gomes FC, Mendes LM. Avaliação do desempenho da madeira na habitação utilizando abordagens de sistemas. Cerne 2005; 11(3):283-293.

Ramalho RS. Dendrologia I: termonologia. Viçosa: UFV; 1975.

Record SJ. Some new names for Tropical American trees of the family Leguminosae. Tropical Woods 1949; 63: 1-6.

Souza MAR, Moutinho VHP, Silva SS. Levantamento das espécies comercializadas vernacularmente como cumaru no Estado do Pará. Revista Brasileira de Biociências 2007; 5(1):81-83.

Tomazello Filho M, Chimelo JP, Garcia PV. Madeiras de espécies florestais do Estado do Maranhão. II. Caracterização anatômica. São Paulo: IPT; 1984. (Boletim do IPT, n. 165).

Van Vliet GLCM, Baas P. Wood anatomy and classification of the Myrtales. Annals of the Missouri Botanical Garden 1984; 71:783-800. http://dx.doi. org/10.2307/2399162

Zenid GJ. Identificação e grupamento das madeiras serradas empregadas na construção civil habitacional na cidade de São Paulo [dissertação]. Piracicaba: Universidade de São Paulo; 1997.

Zenid GJ. Madeira: uso sustentável na construção civil. São Paulo: Instituto de Pesquisas Tecnológicas; 2009.

Zimmermann MH. Functional xylem anatomy of angiosperm trees. In: Baas $\mathrm{P}$, editor. New perspectives in wood anatomy. Boston: Martinus Nijhoff, Dr. Junk Publishers; 1982.

Zimmermann MH. Xylem structure and the ascent of sap. Berlin: Springer-Verlag; 1983. 